\title{
VALUTAZIONE DELLA CLEARANCE DI HCV-RNA SOTTO TRATTAMENTO ANTIVIRALE CON TRANSCRIPTION-MEDIATED AMPLIFICATION (TMA)
}

\author{
Ferraro D., Giglio M., Pizzillo P., Cardinale F., Di Marco V., \\ Craxì A., Di Stefano R. \\ Dipartimento di lgiene e Microbiologia e \\ Dipartimento Biomedico di Medicina Interna e Specialistica, \\ Università di Palermo
}

Background. Il parametro virologico di risposta alla terapia antivirale per l'epatite cronica $\mathrm{C}$ è la negatività di HCVRNA, valutata a fine trattamento (ETR) e dopo 24 settimane (SVR). La riduzione della carica virale in corso di terapia (OTR) ha elevato valore predittivo per la SVR. Il test Amplicor $\mathrm{HCV}^{\mathrm{TM}}$, Roche, attualmente impiegato per la ricerca di HCV-RNA, ha una sensibilità di $50 \mathrm{UI} / \mathrm{ml}$.

La recidiva di infezione, dopo una OTR o una ETR, potrebbe essere predetta da una metodica analitica a più elevata sensibilità.

Obiettivi. Valutare se l'impiego del TMA ${ }^{\mathrm{TM}}$, Bayer; (sensibilità $5-10 \mathrm{UI} / \mathrm{ml}$ ) permetta di individuare fra i pazienti, classificati come OTR o ETR, coloro che non abbiano realmente negativizzato l'HCV-RNA.

Pazienti e metodi: Sono stati esaminati 77 pazienti con epatite cronica $\mathrm{C}$, genotipo $1 \mathrm{~b}$, trattati con PEG-IFN alfa-2b o IFN alfa-2b in combinazione con ribavirina. La OTR è stata valutata a 12 e 24 settimane di terapia, e la ETR e SVR ai tempi predefiniti. I risultati ottenuti con il test Amplicor $\mathrm{HCV}^{\mathrm{TM}}$ sono stati rivalutati mediante $\mathrm{TMA}^{\mathrm{TM}}$.

Risultati e conclusioni. I dati ottenuti confermano la maggiore sensibilità del TMA rispetto all'Amplicor. Dieci pazienti Amplicor -vi sono risultati TMA +vi a 12 settimane; di essi, 3 erano SVR, 2 avevano un breakthrough e 4, pur ottenendo una ETR, mostravano una successiva recidiva. I dati a 24 settimane mostrano valori discordanti nei pazienti BT e ETR. Il valore predittivo positivo (PPV) per una SVR a 12, 24 e 48 settimane di trattamento non ha evidenziato una differenza significativa tra $i$ due tests.

La possibilità offerta da una metodica a più elevata sensibilità di identificare durante le varie fasi del trattamento antivirale pazienti con viremia bassa, ma non assente, consente di ottimizzare il valore predittivo di una regola di interruzione precoce (12 settimane) della terapia in caso di inefficacia. 